\title{
Comorbidities and polypharmacy among HIV-positive patients aged 50 years and over: a case-control study
}

\author{
José Antonio Mata-Marín ${ }^{1 *}$ (D), Moisés Hermilo Martínez-Osio², Carla I. Arroyo-Anduiza ${ }^{4}$, María de \\ los Ángeles Berrospe-Silva ${ }^{3}$, Alberto Chaparro-Sánchez ${ }^{1}$, Itzel Cruz-Grajales ${ }^{2}$, Javier Enrique Cruz-Herrera ${ }^{5}$, \\ Luis Antonio Uribe-Noguez ${ }^{1}$, Jesus E. Gaytán-Martínez ${ }^{1}$ and Medardo Jerónimo-Morales²
}

\begin{abstract}
Objective: This study was to determine and compare the prevalences of polypharmacy and comorbidities in patients aged 50 years or older with those patients younger than 50 years in a Mexican population.

Results: One hundred and twenty-five patients were enrolled, 60 (48\%) were aged 50 years or older. The median CD4+ cell counts were 509 cells/ $\mu \mathrm{L}$ (interquartile range [IQR]: 324-730) for the older patients and 384 cells/ $\mu \mathrm{L}$ (IQR: 262-562) $(P=0.021)$ for the younger patients. Viral suppression were significantly higher in the older group: $80 \%$ vs. 63\% $(P=0.037)$. The number of comorbidities was significantly higher in the older group, with a median of 2 (IQR: $2-3)$ vs. 1 (IQR: $0-1)(P \leq 0.001)$. After adjustment of the logistic regression model in the older group, the following comorbidities differed between the age groups: systemic arterial hypertension (odds ratio [OR]: 15.75; 95\% confidence interval [CI] 3.49-71.05; $P=<0.001$ ), diabetes mellitus (OR: 14.36; 95\% Cl 1.79-115.07; $P=0.001$ ), osteoarthritis (OR: 10.33; 95\% Cl 2.88-37.05; $P=<0.001$ ), hyperlipidemia (OR: 2.78; 95\% Cl 1.22-6.34; $P=0.001$ ), and polypharmacy (OR: 6.58; $95 \% \mathrm{Cl} 3.01-14.39 ; P=0.001$ ).
\end{abstract}

Keywords: Comorbidity, HIV, Polypharmacy

\section{Introduction}

The survival rate and number of people infected with human immunodeficiency virus 1 (HIV-1) who are older than 50 years have increased since the introduction of antiretroviral therapy (ART) in the 1990s [1]. An unexpected increase in the number of comorbidities, such as diabetes mellitus, systemic arterial hypertension, obesity, and dyslipidemia, which are associated with aging, has been documented in older people with HIV-1. Consequently, the number of drugs used and prevalence of polypharmacy among older HIV-infected people have also increased [2].

\footnotetext{
*Correspondence: jamatamarin@gmail.com

${ }^{1}$ Infectious Diseases Department, Instituto Mexicano del Seguro Social, Hospital de Infectología, "La Raza" National Medical Center, IMSS, Seris y Jacarandas s/n, colonia la raza, Del Azcapotzalco, PO. 02990 Mexico City, Mexico

Full list of author information is available at the end of the article
}

The number of comorbidities, level of polypharmacy including ART, and number of physiological age-related changes in various organs and systems can lead to adverse effects and drug interactions, which may affect the clinical condition, lifespan, and quality of life of older HIV-infected people [3]. Several reports have suggested that ART and HIV-1 may increase the risk of chronic comorbid diseases such as hyperlipidemia, atherosclerosis, and osteoporosis $[4,5]$. One study found that HIVinfected patients older than 55 years had, on average, four more comorbidities than patients who were younger than 45 years [6].

Many comorbidities are associated with increased drug use, and polypharmacy is associated with an increased risk of mortality in elderly patients [7]. This risk may be higher in people infected with HIV, although the prevalence of polypharmacy has not been examined thoroughly in older HIV-infected people. One cohort study 
conducted in 2010 reported that $22 \%$ of patients older than 45 years used $\geq 10$ drugs, including ART. The greater use of drugs was generally related to a greater need for non-ART medications [8]. In the Veterans Aging Cohort Study, the average number of daily long-term medications increased with age. Among patients 50 years and older, $55 \%$ were using $\geq 5$ daily medications [9].

The aim of this study was to identify and compare the prevalences of polypharmacy and comorbidities between HIV-infected patients aged 50 years or older and those younger than 50 years in a Mexican population.

\section{Main text}

\section{Materials and methods}

\section{Design}

We performed a case-control study of adult patients infected with HIV-1. Cases included patients aged 50 years or older who were followed as outpatients for $\geq 6$ months and control patients who were treated similarly but were younger than 50 years.

\section{Patients}

The recruited patients were $>16$ years of age, and their infections with HIV-1 had been previously confirmed by enzyme-linked immunosorbent assay (ELISA) and Western blot analysis. The patients were followed as outpatients for at least 6 months and stratified according to age: $<50$ years and $\geq 50$ years at the time of enrollment in the study.

\section{Ethics statement}

The study was conducted in accordance with current ethical considerations and was approved for the research protocol from the Ethics and Investigation Committee of "La Raza" National Medical Center (approval number R-2015-3502-148). Written informed consent was required before a patient was given the questionnaire.

\section{Measurements}

The comorbidities researched included systemic arterial hypertension, dyslipidemia, diabetes mellitus, osteoarthritis, acid peptic disease, chronic kidney disease, heart disease, chronic obstructive pulmonary disease, liver disease, and obesity.

Body mass index (BMI) was defined as body mass divided by the square of body height $\left(\mathrm{kg} / \mathrm{m}^{2}\right)$, and obesity was defined as a BMI $>30 \mathrm{~kg} / \mathrm{m}^{2}$. Osteoarthritis was defined as articular pain lasting $>6$ months that was not associated with an uncontrolled or acute disease. Chronic obstructive pulmonary disease was defined by using spirometry and by the presence of post-bronchodilator forced expiratory volume 1 and forced vital capacity $\left(\mathrm{FEV}_{1} / \mathrm{FVC}\right)<0.7$. Acid peptic disease was defined as symptoms and signs along with consumption of antacids and/or imaging study results that were compatible with the disease, as documented in the clinical file. Liver disease was defined using the set of clinical and laboratory test results for $>6$ months that were consistent with the imaging studies that could not be explained by other uncontrolled disease. Chronic kidney disease was defined according to the Modification in Diet Renal Disease [10] definition as creatinine clearance $<60 \mathrm{~mL} / \mathrm{min} / 1.73 \mathrm{~m}^{2}$ for $\geq 6$ months with previous ART and without the presence of acute or uncontrolled disease. Dyslipidemia was defined as a serum triglyceride concentration $\geq 150 \mathrm{mg} /$ $\mathrm{dL}$ and/or cholesterol concentration $\geq 200 \mathrm{mg} / \mathrm{dL}$ in $\geq 2$ determinations. Diabetes mellitus was defined as follows: a fasting blood glucose concentration $\geq 126 \mathrm{mg} / \mathrm{dL}$ or a blood glucose concentration $\geq 200 \mathrm{mg} / \mathrm{dL}$ in any determination, a glycated hemoglobin level $\geq 6.5 \%$, or patientreported illness and use of antihyperglycemic drugs or insulin. Polypharmacy was defined as the use of five or more concomitant medications. Five concomitant medications is generally accepted as the threshold associated with negative health outcomes [11]. Heart disease was identified as heart failure and/or coronary artery disease. Heart failure was defined based on the symptoms reported by the patient and the prior treatment recorded in the medical history. Coronary artery disease was identified if it was recorded in the clinical record.

\section{Statistical analysis}

The data were summarized using the median and interquartile range (IQR) for continuous variables and proportion for categorical variables. Bivariate analysis was performed to evaluate the risk for comorbidities and polypharmacy and to obtain the odds ratio (OR) using the Chi-squared test and Fisher's exact test. Independent risk factors associated with polypharmacy and the number of comorbidities in each group were identified in the logistic regression analysis, which included the significant variables from the bivariate analysis. All analyses were conducted using SPSS software (version 22; SPSS IBM Corp., Armonk, NJ, USA).

\section{Results}

Of the 131 patients invited to participate in the study, 125 agreed to participate, and $60(48 \%)$ of these patients were aged 50 years or older. The median age was 55.5 years (IQR: $52-59.7$ ) in the older group and 31 years (IQR: $26-36)$ in the younger group. Both groups included fewer women than men: $16 \%$ of the older group and $8 \%$ of the younger group were women.

The median CD4 + cell counts of patients who were outpatients of the medical center for $\geq 6$ months were 509 cells $/ \mu \mathrm{L}$ (IQR: $324-730$ ) in the older group and 
384 cells/ $\mu \mathrm{L}$ (IQR: 262-562) in the younger group $(P=0.021) ; 80 \%$ of the older group and $63 \%$ of the younger group exhibited viral suppression $(P=0.015)$ (Table 1).

The most prevalent drugs used were as follows: antihypertensive agents, which were used by 21 (35\%) older patients and $2(3.1 \%)$ younger patients (OR: 11.37 ; $95 \% \mathrm{CI}$ 2.75-46.6; $P<0.001)$; hypolipidemic drugs, which were used by $17(28.3 \%)$ older patients and $2(3.1 \%)$ younger patients (OR: 9.2; 95\% CI 2.22-38.19; $P<0.001$ ); nonsteroidal anti-inflammatory drugs (NSAIDs), which were used by $14(23.3 \%)$ older patients and $4(6.2 \%)$ younger patients (OR: 3.79; 95\% CI 1.32-10.88; $P=0.006$ ); and anticonvulsants/anxiolytics, which were used by 14 (23.3\%) older patients and $4(6.2 \%)$ younger patients (OR: 3.79; 95\% CI 1.32-10.88; $P=0.009$ ) (Table 2).

\section{Comorbidities}

The median number of comorbidities was 2 (IQR: 2-3) in the older group and 1 (IQR: $0-1$ ) in the younger group $(P \leq 0.001)$. The following comorbidities differed significantly between the older and younger groups: systemic arterial hypertension in $20(33 \%)$ of the older patients and $2(3.1 \%)$ of the younger patients (OR: 15.1; 95\% CI $3.3-68.1 ; P \leq 0.001)$; diabetes mellitus in $11(18.3 \%)$ of the older patients and $1(1.5 \%)$ of the younger patients (OR: 13.8; 95\% CI 1.7-110.9; $P=0.002$ ); hyperlipidemia in $49(81.7 \%)$ of the older patients and $40(61.5 \%)$ of the younger patients (OR: 2.9; 95\% CI 1.2-6.6; $P=0.009$ ); osteoarthritis in $20(33.3 \%)$ of the older patients and 3 (4.6\%) of the younger patients (OR: 9.9; 95\% CI 2.7-35.5; $P<0.001)$; acid peptic disease in $12(20 \%)$ of the older patients and $4(6.2 \%)$ of the younger patients (OR: 3.6; 95\% CI 1.1-12.1; $P=0.032)$; and obesity in $11(18.3 \%)$ of

Table 1 Profile characteristics of infection $(n=125)$

\begin{tabular}{|c|c|c|c|}
\hline Characteristics & Age $<50$ years, $n=65\left(I Q R^{*}\right)$ & Age $\geq 50$ years, $n=60\left(I Q R^{*}\right)$ & $P$ value \\
\hline Years since diagnosis & $1(0.8-3.5)$ & $7(2-16)$ & $<0.001$ \\
\hline cD4+ cell count, cells $/ \mathrm{mm}^{3}$ & $384(262-562)$ & $509(324-730)$ & 0.021 \\
\hline HIV $\log _{10}$ HIV RNA & $1.27(1.27-2.24)$ & $1.27(1.27-1.27)$ & 0.003 \\
\hline HIV RNA viral load $<50$ copies/mL ${ }^{\mathrm{a}}$, number (\%) & $41(63 \%)$ & $48(80 \%)$ & 0.015 \\
\hline Total number of drugs used, ART plus non-ART & $4(3-5)$ & $6(4-8)$ & $<0.001$ \\
\hline Total number of ART drugs used ${ }^{b}$ & $3(3-4)$ & $4(3-4)$ & 0.002 \\
\hline Total number of comorbidities found & $2(1-3)$ & $3.5(2-5)$ & $<0.001$ \\
\hline $\mathrm{BMI}, \mathrm{kg} / \mathrm{m}^{2}$ & $23.75(21.61-26.05)$ & $25.52(22.96-28.51)$ & 0.018 \\
\hline Accumulated exposure/smoking index & $0.1(0-0.75)$ & $0.1(0-9.7)$ & $<0.001$ \\
\hline
\end{tabular}

*Data are presented as the median (IQR) unless indicated otherwise

a Per $\log _{10}$ copies/mL increase (centered at 1.30, level of detection)

b Only patients with current ART (9 younger patients did not have medically indicated treatment)

Table 2 Characteristics of non-ART drugs used $(n=125)$

\begin{tabular}{|c|c|c|c|c|}
\hline Characteristic & Age $<50$ years, $n=65$ & Age $\geq 50$ years, $n=60$ & Odds ratio $(95 \% \mathrm{Cl})$ & $P$ value \\
\hline Polypharmacy & $17(26.5 \%)$ & $42(23.3 \%)$ & $6.58(3.01-14.39)$ & $<0.001$ \\
\hline Antihypertensive medication & $2(3.1 \%)$ & $21(35 \%)$ & $11.37(2.75-46.46)$ & $<0.001$ \\
\hline Antihyperglycemic medication & $2(3.1 \%)$ & $17(28.3 \%)$ & $9.2(2.22-38.19)$ & $<0.001$ \\
\hline NSAIDs & $4(6.2 \%)$ & $14(23.3 \%)$ & $3.79(1.32-10.88)$ & 0.009 \\
\hline Anticonvulsants/anxiolytics & $4(6.2 \%)$ & $14(23.3 \%)$ & $3.79(1.32-10.88)$ & 0.009 \\
\hline Current sildenafil use & $6(9.2 \%)$ & $14(23.3 \%)$ & $2.52(1.03-6.15)$ & 0.032 \\
\hline Antacid & $4(6.2 \%)$ & $12(20 \%)$ & $3.25(1.1-9.53)$ & 0.03 \\
\hline Antihyperglycemic agents & $1(1.5 \%)$ & $11(18.3 \%)$ & $11.91(1.58-89.54)$ & 0.001 \\
\hline Vitamins/minerals & $1(1.5 \%)$ & $11(18.3 \%)$ & $11.91(1.58-89.54)$ & 0.002 \\
\hline Antidepressants & $4(6.4 \%)$ & $4(6.2 \%)$ & $1.08(0.28-4.14)$ & 1.0 \\
\hline Antibiotics & $11(16.9 \%)$ & $3(5 \%)$ & $0.29(0.08-0.98)$ & 0.047 \\
\hline Diuretics & $1(1.5 \%)$ & $2(3.3 \%)$ & $2.16(0.2-23.28)$ & 0.60 \\
\hline Food supplements & $0(0 \%)$ & $3(5 \%)$ & & 0.10 \\
\hline
\end{tabular}


the older patients and $3(4.6 \%)$ of the younger patients (OR: 4.4; 95\% CI 1.1-16.9; $P=0.023$ ) (Table 3).

\section{Polypharmacy}

Polypharmacy differed significantly between the age groups: 42 (70\%) older patients and $17(26.2 \%)$ younger patients met the criteria for polypharmacy (OR: 6.58; 95\% CI 3.01-14.39; $P<0.001)$. The median number of drugs used concomitantly was 6 (IQR: $4-8$ ) in the older group and 4 (IQR: $3-5)$ in the younger group $(P<0.001)$.

After adjustment of the logistic regression model in the older group, the following comorbidities differed between the age groups: systemic arterial hypertension (odds ratio [OR]: 8.8 ; 95\% confidence interval $[\mathrm{CI}]$ 1.42-52.72; $P=0.017$ ), osteoarthritis (OR: $11.84 ; 95 \% \mathrm{CI}$ 2.72-50.9; $P=0.001$ ), hyperlipidemia (OR: $2.8 ; 95 \% \mathrm{CI}$ $1.03-7.64 ; P=0.042$ ), and polypharmacy (OR: $6.58 ; 95 \%$ CI 3.01-14.39; $P=0.001$ ).

\section{Discussion}

Since 1996, ART has increased the survival rate and number of older people with HIV infection. ART is associated with a decrease in morbidity and mortality related to acquired immunodeficiency syndrome (AIDS) [10]. However, the prevalence of age-related comorbidities and the number of drugs related to the comorbidities have increased unexpectedly in older HIV-infected people [2, $11]$.

In this study, the prevalence of polypharmacy was significantly higher in the older group than in the younger group. The comorbidities independently associated with older age were systemic arterial hypertension, hyperlipidemia, and osteoarthritis.
According to a prediction, in 2030, $84 \%$ of HIVinfected patients will have at least one age-related noncommunicable disease and $28 \%$ will have three or more [12]. Our data are similar to those of Marzolini et al., who found that older patients were more likely to use one or more comedications than younger patients ( $82 \%$ vs. $61 \%$; $P<0.001$ ) [13]. Moreover, as observed in the older group in the current study, the older patients in the study by Marzolini et al. tended to use comedications and certain therapeutic drug classes, such as cardiovascular drugs (53\% vs. $19 \% ; P<0.001$ ) and gastrointestinal medications ( $10 \%$ vs. $6 \% ; P=0.004)$, more often than the younger group. Another study showed that 147 of 165 (89\%) patients had comorbid conditions (mean number of conditions, 2.4) and that $133(81 \%)$ received HIV-unrelated medications (mean number of medications, 2.7) [14]. Geriatric syndromes such as cognitive impairment, urinary incontinence, falls, fractures, dementia, and fragility are more likely to occur in the setting of polypharmacy, which is increasingly relevant to HIV care as patients age in the era of combination ART $[15,16]$.

Hasse et al. reported that comorbidity and multimorbidity associated with non-AIDS diseases, particularly diabetes mellitus, cardiovascular disease, non-AIDSdefining malignancies, and osteoporosis, increase with age and become more important in the care of HIVinfected persons [17].

In this study was shown that HIV-infected individuals aged $>50$ years had better virological responses to ART and CD4+T-cell counts compared with younger patients [18]. These results are consistent with prior studies, who demonstrate better outcomes among older patients [19-21]. While other studies no differences in virological response to ART by age [22-24]; the reason

Table 3 Prevalence of the comorbidities investigated $(n=125)$

\begin{tabular}{|c|c|c|c|c|}
\hline Comorbidity & Age $<50$ years, $n=65$ & Age $\geq 50$ years, $n=60$ & Odds ratio $(95 \% \mathrm{Cl})$ & $P$ value \\
\hline Systemic arterial hypertension & $2(3.1 \%)$ & $20(33 \%)$ & $15.1(3.3-68.1)$ & $<0.001$ \\
\hline Osteoarthritis & $3(4.6 \%)$ & $20(33.3 \%)$ & $9.9(2.7-35.5)$ & $<0.001$ \\
\hline Hyperlipidemia & $40(61.5 \%)$ & $49(81.7 \%)$ & $2.9(1.2-6.6)$ & 0.009 \\
\hline Diabetes mellitus & $1(1.5 \%)$ & $11(18.3 \%)$ & $13.8(1.7-110.9)$ & 0.002 \\
\hline Acid peptic disease & $4(6.2 \%)$ & $12(20 \%)$ & $3.6(1.15-12.1)$ & 0.032 \\
\hline Obesity, BMI > 30 kg/m² & $3(4.6 \%)$ & $11(18.3 \%)$ & $4.47(1.18-16.9)$ & 0.023 \\
\hline HBV coinfection & $6(9.2 \%)$ & $11(18.3 \%)$ & $2.12(0.73-6.16)$ & 0.158 \\
\hline Heart failure and/or coronary heart disease & $1(1.5 \%)$ & $1(1.7 \%)$ & $1.05(0.64-17.16)$ & 1.0 \\
\hline Chronic kidney disease & $3(4.6 \%)$ & $4(6.7 \%)$ & $1.42(0.30-6.65)$ & 0.713 \\
\hline Current malignant tumors & $2(2.7 \%)$ & $4(6.7 \%)$ & $2.25(0.39-12.75)$ & 0.348 \\
\hline Current sexually transmitted disease & $21(32.3 \%)$ & $11(18.3 \%)$ & $0.47(0.20-1.08)$ & 0.074 \\
\hline Liver disease & $0(0 \%)$ & $2(3.3 \%)$ & & 0.138 \\
\hline Chronic obstructive pulmonary disease & $0(0 \%)$ & $1(1.7 \%)$ & & 0.296 \\
\hline
\end{tabular}

Data are presented as the number (\%) 
for the discrepancy between the CD4+ cell count and virological responses to ART may be the lag between diagnosis of HIV/AIDS and higher ART adherence was the key factor for older patients, who must overcome potential obstacles to a robust response, including an increased risk of adverse events, a higher comorbidity, and possible age-related immune senescence [10].

A small cross-sectional national health and nutritional examination survey found that HIV-infected elderly patients had higher prevalences of hypertension, hypertriglyceridemia, low bone mineral density, and lipodystrophy than the controls that were matched 1:1 by age, race, gender, smoking status and BMI [24]. This result suggests that the effects of HIV and treatment-related factors contribute to the development of these conditions more than does "normal" aging. Most studies have reported hypertension and cardiovascular risk factors as the main comorbidities; these are also among the leading causes of death worldwide $[5,17,24]$.

\section{Conclusion}

Among the comorbidities studied, systemic arterial hypertension, osteoarthritis, hyperlipidemia, and polypharmacy were more frequent in the older patients.

\section{Limitations}

Our study has several limitations. The study included a small sample size, and certain variables could not be controlled. There may have been selection bias in choosing the cases and controls. Another limitation is related to study population, only were included HIV infected patients; therefore, it need more comparative studies with HIV-uninfected people. Most of the patients in both groups were men, hindering the extrapolation of our findings about the prevalence of comorbidities and polypharmacy in women. Moreover, our results can be generalized only to male populations with similar characteristics. However, the data from this study are clinically relevant given the lack of similar studies on the prevalence of comorbidities and polypharmacy in the older Mexican HIV-infected population. Observational studies may more closely approximate the prevalence of specific diseases in clinical practice. The case-control design allowed us to estimate the relative risks for diseases or events, which was the aim of our study. Further prospective studies of elderly patients are needed to individualize treatment for patients with polypharmacy and comorbidities.

\section{Abbreviations}

AIDS: acquired immuno deficiency syndrome; ART: antiretroviral therapy; BMI: body mass index; Cl: confidence interval; ELISA: enzyme-linked immunosorb-

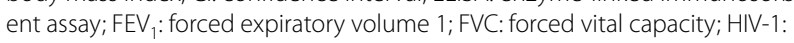
human immunodeficiency virus; IQR: interquartile range; NSAIDs: nonsteroidal anti-inflammatory drug; OR: odds ratio.

\section{Acknowledgements}

The authors wish to thank all centers and investigators who participated in this study.

\section{Authors' contributions}

All named authors have met the International Committee of Medical Journal Editors (ICMJE) criteria for authorship for this manuscript, have taken responsibility for the integrity of the work as a whole, and have provided final approval of the version to be published. MHMO conceptualized and designed the study, drafted the manuscript, and provided final approval of the version to be published. JAMM conceptualized and designed the study, drafted the manuscript, and provided final approval of the version to be published. CIAA and ACS collected the data, wrote parts of the manuscript, reviewed the project, and provided final approval of the version to be published. MABS, LAUN and JECH wrote parts of the manuscript, reviewed the project and provided final approval of the version to be published. ICG wrote parts of the manuscript, provided final approval of the version to be published. JEGM reviewed the project, provided final approval of the version to be published. MJM collected the data, provided final approval of the version to be published. The corresponding author was responsible for ensuring that all listed authors have approved the manuscript before submission, including the names and order of the authors, and that all authors received the submission and all substantive correspondence with the editors, as well as the complete reviews, verifying that all data, figures, materials (including reagents) and code, including those developed or provided by other authors, comply with the standards of transparency and reproducibility of both the field and the journal. All authors read and approved the final manuscript.

\section{Funding}

No funding or sponsorship was received for this study or publication of this article. The project was supported by the authors.

\section{Availability of data and materials}

All data generated or analyzed during this study are included in this published article and its additional information files.

\section{Ethics approval and consent to participate}

All procedures followed were in accordance with the ethical standards of the responsible committee on human experimentation (Ethics and Investigation Committee of "La Raza" National Medical Center) and with the Helsinki Declaration of 1964, as revised in 2013. Written informed consent was obtained from all patients before their inclusion in the study.

\section{Consent for publication}

Not applicable.

\section{Competing interests}

The authors Antonio Mata, Moises Martínez, Carla Arroyo, María de los Ángeles Berrospe, Alberto Chaparro, Itzel Cruz, Javier Cruz, Luis Uribe, Jesus Gaytán, Jerónimo Morales, declare that they have no competing interests.

\section{Author details}

${ }^{1}$ Infectious Diseases Department, Instituto Mexicano del Seguro Social, Hospital de Infectología, "La Raza” National Medical Center, IMSS, Seris y Jacarandas s/n, colonia la raza, Del Azcapotzalco, PO. 02990 Mexico City, Mexico. ${ }^{2}$ Internal Medicine Department, Hospital General, "La Raza" National Medical Center, IMSS, Mexico City, Mexico. ${ }^{3}$ Infectious Diseases Department, Instituto Mexicano del Seguro Social, Unidad de Infectología "Juan I. Menchaca", Ext HGR 45, IMSS, Guadalajara, Jalisco, Mexico. ${ }^{4}$ Clinical Pathology Department, Banco Central de Sangre, Hospital de Especialidades, "La Raza" National Medical Center, IMSS, Mexico City, Mexico. ${ }^{5}$ Internal Medicine Department, Hospital HGZ-\# 3, Querétaro, Mexico. 
Received: 19 June 2018 Accepted: 21 August 2019

Published online: 03 September 2019

\section{References}

1. Paterson DL, Swindells S, Mohr J, et al. Adherence to protease inhibitor therapy and outcomes in patients with HIV infection. Ann Intern Med. 2000;133(1):21-30. https://doi.org/10.7326/0003-4819-133-1-20000704000004.

2. Sackoff JE, Hanna DB, Pfeiffer MR, Torian LV. Causes of death among persons with AIDS in the era of highly active antiretroviral therapy: New York City. Ann Intern Med. 2006;145(6):397-406. https://doi.org/10.7326/00034819-145-6-200609190-00003

3. Miller CD, El-Kholi R, Faragon JJ, Lodise TP. Prevalence and risk factors for clinically significant drug interactions with antiretroviral therapy. Pharmacotherapy. 2007;27(10):1379-86. https://doi.org/10.1592/ phco.27.10.1379.

4. Anuurad E, Semrad A, Berglund L. Human immunodeficiency virus and highly active antiretroviral therapy-associated metabolic disorders and risk factors for cardiovascular disease. Metab Syndr Relat Disord. 2009;7(5):401-10. https://doi.org/10.1089/met.2008.0096.

5. Goulet JL, Fultz SL, Rimland D, et al. Aging and infectious diseases: do patterns of comorbidity vary by HIV status, age, and HIV severity? Clin Infect Dis. 2007;45(12):1593-601. https://doi.org/10.1086/523577.

6. Ship JA, Wolff A, Selik RM. Epidemiology of acquired immune deficiency syndrome in persons aged 50 years or older. J Acquir Immune Defic Syndr. 1991;4(1):84-8. https://doi.org/10.1097/00126334-19910100000012.

7. Sitar DS. Aging issues in drug disposition and efficacy. Proc West Pharmacol Soc. 2007:50:16-20.

8. Krentz HB, Cosman I, Lee K, Ming JM, Gill MJ. Pill burden in HIV infection: 20 years of experience. Antivir Ther. 2012;17(5):833-40. https://doi. org/10.3851/IMP2076.

9. Edelman EJ, Gordon KS, Glover J, McNicholl IR, Fiellin DA, Justice AC The next therapeutic challenge in HIV: polypharmacy. Drugs Aging. 2013;30(8):613-28. https://doi.org/10.1007/s40266-013-0093-9.

10. Perez JL, Moore RD. Greater effect of highly active antiretroviral therapy on survival in people aged $>$ or $=50$ years compared with younger people in an urban observational cohort. Clin Infect Dis. 2003;36(2):212-8. https://doi.org/10.1086/345669.

11. Gimeni GM, Crusells CM, Armesto GJ, Compaired-Turlán V, Rabanaque HM. Polipharmacy in older adults with human immunodeficiency virus infection compared with the general population. Clin Interv Aging. 2016;11:1149-57.

12. Smit M, Brinkman $K$, Geerlings $S$, et al. Future challenges for clinical care of an ageing population infected with HIV: a modelling study. Lancet Infect Dis. 2015;15(7):810-8. https://doi.org/10.1016/S1473 -3099(15)00056-0.
13. Marzolini C, Back D, Weber R, et al. Ageing with HIV: medication use and risk for potential drug-drug interactions. J Antimicrob Chemother. 2011;66(9):2107-11. https://doi.org/10.1093/jac/dkr248.

14. Shah SS, McGowan JP, Smith C, Blum S, Klein RS. Comorbid conditions, treatment, and health maintenance in older persons with human immunodeficiency virus infection in New York City. Clin Infect Dis. 2002;35(10):1238-43. https://doi.org/10.1086/343048.

15. Gianotti N, Galli L, Bocchiola B, et al. Number of daily pills, dosing schedule, self-reported adherence and health status in 2010: a large crosssectional study of HIV-infected patients on antiretroviral therapy. HIV Med. 2013;14(3):153-60. https://doi.org/10.1111/j.1468-1293.2012.01046 $x$.

16. Shah BM, Hajjar ER. Polypharmacy, adverse drug reactions, and geriatric syndromes. Clin Geriatr Med. 2012;28(2):173-86. https://doi.org/10.1016/j. cger.2012.01.002.

17. Hasse $B$, Ledergerber $B$, Furrer $H$, et al. Morbidity and aging in HIV-infected persons: the Swiss HIV cohort study. Clin Infect Dis. 2011;53(11):1130-9. https://doi.org/10.1093/cid/cir626.

18. Goodkin K, Shapshak P, Asthana D, et al. Older age and plasma viral load in HIV-1 infection. AIDS. 2004;18(suppl 1):S87-98. https://doi. org/10.1097/00002030-200418001-00013.

19. Grabar S, Kousignian I, Sobel A, et al. Immunologic and clinical responses to highly active antiretroviral therapy over 50 years of age: results from the French Hospital Database on HIV. AIDS. 2004;18:2029-38.

20. Anastos K, Schneider MF, Gange SJ, et al. The association of race, sociodemographic, and behavioral characteristics with response to highly active antiretroviral therapy in women. J Acquir Immune Defic Syndr. 2005;39:537-44.

21. Uphold CR, Maruenda J, Yarandi HN, Sleasman JW, Bender BS. HIV and older adults: clinical outcomes in the era of HAART. J Gerontol Nurs. 2004;30(16-24):55-66. https://doi.org/10.3928/0098-9134-20040701-06.

22. Work Group for The HIV and Aging Consensus Project. Summary report from the human immunodeficiency virus and aging consensus project: treatment strategies for managing older individuals with human immunodeficiency virus. J Am Geriatr Soc. 2012;60(5):974-9. https://doi.org/10. 1111/j.1532-5415.2012.03948.x

23. Tumbarello M, Rabagliati R, de Gaetano Donati K, et al. Older age does not influence CD4 cell recovery in HIV-1 infected patients receiving highly active antiretroviral therapy. BMC Infect Dis. 2004;4:e46. https://doi. org/10.1186/1471-2334-4-46.

24. Onen NF, Overton ET, Seyfried W, et al. Aging and HIV infection: a comparison between older HIV-infected persons and the general population. HIV Clin Trials. 2010;11(2):100-9. https://doi.org/10.1310/hct1102-100.

\section{Publisher's Note}

Springer Nature remains neutral with regard to jurisdictional claims in published maps and institutional affiliations.
Ready to submit your research? Choose BMC and benefit from:

- fast, convenient online submission

- thorough peer review by experienced researchers in your field

- rapid publication on acceptance

- support for research data, including large and complex data types

- gold Open Access which fosters wider collaboration and increased citations

- maximum visibility for your research: over 100M website views per year

At $\mathrm{BMC}$, research is always in progress.

Learn more biomedcentral.com/submissions 